\title{
Effects of Preservatives on Corneal Collagen Parameters Measured by Small Angle X-ray Scattering Analysis
}

Susyn Kelly ( $\square$ susynkelly@gmail.com )

Ross University School of Veterinary Medicine https://orcid.org/0000-0002-6151-545X

Lizette duPlessis

University of Pretoria

John Soley

University of Pretoria

Frazer Noble

Massey University - Albany Campus

Hannah Catherine Wells

Massey University

\section{Patrick John Kelly}

Ross University School of Veterinary Medicine

\section{Research}

Keywords: Collagen, SAXS, cornea, formalin, glutaraldehyde, Triton X

Posted Date: May 28th, 2020

DOI: https://doi.org/10.21203/rs.3.rs-31473/v1

License: (1) This work is licensed under a Creative Commons Attribution 4.0 International License. Read Full License 


\section{Abstract}

Background: Collagen is a prominent structural protein in biological tissue, and little is known about the effect of preservatives, commonly used to preserve and study tissue, on collagen structures.

Method: The study determined the effects of commonly used tissue preservatives on measurements of fibril diameter, fibril diameter distribution, and D-spacing of corneal collagen made using small angle Xray scattering (SAXS) analysis.

Results: Compared to control sheep and cats' corneas that were preserved frozen at $-80{ }^{\circ} \mathrm{C}$, those preserved in $5 \%$ glutaraldehyde and $10 \%$ formalin had significantly larger mean collagen fibril diameters, increased fibril diameter distribution and decreased D-spacing. Corneas preserved in Triton X had significantly increased mean collagen fibril diameters and orientation indexes with decreased fibril diameter distribution. Corneas preserved in $0.9 \%$ saline had significantly increased mean collagen fibril diameters and decreased diameter distributions. Subjectively, the corneas preserved in $5 \%$ glutaraldehyde and $10 \%$ formalin maintained their transparency but those in Triton $X$ and $0.9 \%$ saline became opaque. Subjective morphological assessment of transmission electron microscope images of corneas supported the SAXS data. Conclusions: Workers using SAXS analysis to characterize collagen should be alerted to changes that can be introduced by common preservatives in which their samples may have been stored.

\section{Background}

Collagen is the most abundant fibrous protein in animals, providing strength and structure to a variety of tissues including the cornea. The basic unit of collagen is a repeating series of three amino acids that form alpha chains which coil together in a triple helix, the basic collagen molecule. The long collagen molecules pack together in a staggered side-by-side fashion to form collagen fibrils that are characterized by areas of high and lower collagen molecule overlap, termed D-spacing. Collagen fibrils can be arranged in a mainly parallel fashion to give strength to the tissue, as seen in tendon for example. They can also be largely random and form a mesh-like structure that provides flexibility and resistance to tear propagation, as in the skin.(1) In the cornea, the collagen fibrils in the stroma are relatively uniform in size and have short-range ordering, which are essential for corneal transparency. $(2,3)$

Small angle X-ray scattering (SAXS) is an analytical method used to determine the nanostructure of materials. When $\mathrm{X}$-rays are passed through a sample they are diffracted by its components and mathematical analysis of the resulting scatter patterns provides information on the shape and size of the components. Typically, SAXS analysis provides structural information on objects between 1 and $400 \mathrm{~nm}$ in size and has the advantages of being non-destructive and requiring minimal sample preparation(4). The technique has been used for the analysis of a wide range of substances, including biological materials where it has been particularly useful in studies of collagen in leather, $(5-8)$ tendon, $(9,10)$ and the cornea,(11-17) most recently to characterize a lesion of veterinary importance.(18) 
The ultrastructure of collagen is often determined by electron microscopy, but to produce the thin tissue sections that are studied, tissues must first undergo chemical preservation, also called fixation. This prevents degradation of tissues by autolysis and putrefaction, stabilizes the ultrastructure, and introduces structural rigidity that facilitates sectioning. Fixation, however, also brings about changes in the size and shape of tissue components and these have been described for collagen when examined by high resolution transmission electron microscopy (TEM).(19) Knowing how fixation changes the ultrastructure is important and the processing method needs to be chosen carefully to preserve features of interest in the studied tissue.

Although SAXS analysis can be carried out on unprocessed tissue, often only fixed samples are available. There is minimal data on the effects of fixation of collagen on the parameters that can be measured by SAXS. Fullwood and Meek(20) found the interfibrillar spacing in bovine corneas fixed in $2.5 \%$ glutaraldehyde in $0.9 \%$ saline was not significantly greater than in fresh corneas $(63.8 \mathrm{~nm} \pm 2.8$ vs. $63.4 \mathrm{~nm} \pm 2.7 ; \mathrm{P}>0.2)$. Although they found the $D$-spacing was significantly decreased $(65.0 \pm 0.2 \mathrm{~nm}$ vs. $64.5 \pm 0.2 \mathrm{~nm} ; \mathrm{P}<0.001$ ), a subsequent study found rat Achilles tendon stored in an unspecified formalin formulation for 48 hours had similar D-spacing to that of tendon in phosphate buffered saline.(21) Freezing of human corneas had no effect on X-ray scattering patterns(15)

To provide further information on the effects of commonly used preservatives on collagen parameters determined by SAXS analysis, treated and untreated sheep and cats' corneas were studied. TEM was performed on all samples to complement the SAXS data.

\section{Methods}

\section{Samples}

Clinically normal corneas were collected from two adult female sheep immediately after slaughter at an abattoir in Fielding, New Zealand. Also, corneas normal on ophthalmological examination were obtained from an adult male cat and a female cat presented for necropsy at the Pathology Department of Massy University School of Veterinary Medicine, Palmerston North, New Zealand. The cats had been humanely euthanized for reasons unrelated to the current study. The central areas of the cats' and sheep corneas where there is the most uniform collagen fibril arrangement $(2,22)$ were divided to provide samples for the following treatments which were carried out in duplicate. As freezing has no effect on X-ray scattering patterns(15), the duplicate normal control samples consisted of two cat and two sheep samples which were immediately wrapped in cling wrap and frozen at $-80^{\circ} \mathrm{C}$. The remaining duplicate samples were immersed in either $2 \mathrm{~mL}$ of $5 \%$ glutaraldehyde, $10 \%$ formalin, Triton $\mathrm{X}$ or $0.9 \%$ saline. Four days later the corneal samples were tested for transparency (below), analysed by SAXS (below), and fixed in Karnovsy's fixative for ultrastructural evaluation by TEM as described below.

\section{Preservatives}


$5 \%$ Glutaraldehyde was formulated from $40 \mathrm{~mL} 25 \%$ glutaraldehyde, $50 \mathrm{~mL} 0.2 \mathrm{M}$ cacodylate buffer and 80 $\mathrm{mL}$ distilled water.

$10 \%$ Formalin was formulated by mixing $100 \mathrm{~mL} 37-40 \%$ formaldehyde, $900 \mathrm{~mL}$ distilled water, monosodium phosphate $(4.0 \mathrm{~g})$ and anhydrous disodium phosphate $(6.5 \mathrm{~g})$.

Triton $X$ was formulated from $20 \mathrm{mM}$ tris-aminomethane with $1 \mathrm{mM}$ ethylenediaminetetraacetic acid, $1.25 \mathrm{~mL} 10 \%$ Triton $X$ and $1.25 \mathrm{~mL}$ sodium deoxycholate.

$0.9 \%$ saline was prepared by dissolving $4.5 \mathrm{~g}$ sodium chloride in $500 \mathrm{~mL}$ deionized water before heat sterilization.

Karnovsky's fixative was made up using $2.0 \mathrm{~g}$ of paraformaldehyde, $5.0 \mathrm{~mL}$ of $50 \%$ glutaraldehyde, and $20.0 \mathrm{~mL}$ of $0.2 \mathrm{M}$ cacodylate buffer before the $\mathrm{pH}$ was adjusted to 7.4 with $1 \mathrm{M}$ sodium hydroxide.

\section{Transparency Test}

The effect of the preservatives on corneal transparency was evaluated subjectively by observing a $4 \mathrm{~mm}$ by $4 \mathrm{~mm}$ cross (1-point black line) through the corneal samples (Figure 1).

\section{Statistical Analysis}

Analyses were performed using Minitab 17 Statistical Software (2010) (State College, PA: Minitab, Inc,; www.minitab.com) for the 2 -sample t-test for unequal variance. A $P<0.05$ was regarded as significant.

\section{Small Angle X-ray Scattering}

The SAXS/WAXS beamline at the Australian Synchrotron in Melbourne, Australia was used to examine the collagen structure of the corneas. The samples were mounted flat-on to the X-ray beam (along their optical axis from anterior to posterior) to perform surface diffraction measurements in which nine diffraction patterns were recorded using a three by three grid with $0.25 \mathrm{~mm}$ spacing between points. A high-intensity undulator source was utilized with an energy resolution of $10^{-4}$ from a cryo-cooled $\mathrm{Si}$ (111) double-crystal monochrometer. The beam size full width half maximum (FWHM) focused at the sample was $250 \times 80 \mu \mathrm{m}$ with a total photon flux of approximately $2 \times 10^{12}$ photons $\mathrm{s}^{-1}$. All diffraction patterns were calibrated with silver behenate and recorded with an X-ray energy of $12 \mathrm{keV}$ using a Pilatus $1 \mathrm{M}$ detector with an active area of $170 \times 170 \mathrm{~mm}$ and a sample detector distance of $3337 \mathrm{~mm}$. The exposure time for diffraction patterns was in the range of $1-5$ seconds. Data processing was carried out using the ScatterBrain software to determine collagen fibril diameters and D-spacing.

\section{D-spacing}


After background subtraction, Gaussian approximations were used to determine the peak position of the maxima of the fifth order diffraction peak from the intensity versus q plot (Figure 2) where q is defined as the magnitude of the scattering vector. The $\mathrm{D}$-spacing was calculated by comparing diffraction peak positions with the calibrant to determine q-values.

Fibril Diameter and Fibril Diameter Distribution

Fibril diameters were determined from the intensity versus q plot over the full q-range $\left(0.01 \AA^{-1}-0.1 \AA^{-1}\right)$ (Figure 2) by expressing the scattered intensities in terms of volume fraction distribution of scatters. Applying the total non-negative least squares model and the 'cylinder AR' model using "Irena" , a macro developed for analysing SAXS data(23) and more specifically particle size distributions in SAXS data running in a data analysis tool (Igor Pro, Wavemetrics, Lake Oswego, OR, USA), the fibril diameter spread within a sample was determined from the scatter intensity patterns, under the assumption that fibrils have a cylindrical shape.

\section{Transmission Electron Microscopy}

The corneas in Karnovsky's fixative were trimmed, washed three times in phosphate buffered saline (0.1 $\mathrm{M}, \mathrm{pH} 7.2$ ) and post-fixed in osmium tetroxide $(0.1 \mathrm{M})$ for one hour. After two additional washes in water, the samples were dehydrated through a graded ethanol series (from $50 \%$ to $100 \%$ in increments of 10 ) and embedded in epoxy resin (TAAB 812 resin kit, England). Ultra-thin sections (70 to $90 \mathrm{~nm}$ ) were cut with a Leica EM UC7 ultra-microtome (Leica EM UC7, Leica, Germany) and mounted on copper grids. Sections were stained with uranyl acetate and lead citrate before being viewed in a Philips CM10 transmission electron microscope (Philips Electron Optical Division, Eindhoven, The Netherlands) operated at $80 \mathrm{kV}$. Images were digitally recorded using the Olympus iTEM Soft Imaging System.

\section{Transmission Electron Microscope Image Processing}

A Graphical User Interface (GUI), written in C++ using the Qt framework and the Open Computer Vision library, was used to detect and measure the collagen fibrils in end-on TEM images of cat and sheep corneas fixated in various preservatives. The GUI allowed the user to compute an image's pixel-tonanometre scale factor and use an algorithm to detect the fibrils' contours. Delaunay triangulation was used on the detected contours to generate a Voronoi diagram, which distinguished one fibril from another. The GUI computed each fibril's diameter and distance between its nearest neighbours.

\section{Results}

\section{Transparency Test}


The printed cross below the sample was clearly visible through the control corneas (Figure 1) and those preserved in $5 \%$ glutaraldehyde and $10 \%$ formalin. It was less clearly visible through the corneas preserved in $0.9 \%$ saline and was not visible through the corneas stored in Triton X.

\section{Small Angle X-ray Scattering}

Scatter patterns and their associated intensity versus q-range plots are shown in Fig. 2 for the sheep and cats' corneas treated with the various preservatives. The 5th order peak used for the D-spacing and the full q-range $\left(0.01-0.1 \AA^{-1}\right)$ was used for fibril diameter measurements. Results for these collagen parameters are presented in Figure 3 and Table 1.

Table 1

Results of small angle $x$-ray scattering analysis to determine average (standard deviation) D-spacing and fibril diameter of sheep and cats' corneas treated with $5 \%$ glutaraldehyde (G), $10 \%$ formalin (F), Triton X $(\mathrm{T})$, and $0.9 \%$ saline (S). P-values relate to a significance test between the various preservatives relative to the control untreated cornea sample values (C).

\begin{tabular}{|c|c|c|c|c|c|c|}
\hline \multirow[t]{2}{*}{ Species } & \multirow[t]{2}{*}{ Collagen Properties } & \multicolumn{4}{|c|}{ Preservatives } & \multirow{2}{*}{$\begin{array}{l}\text { Control } \\
\text { C }\end{array}$} \\
\hline & & G & $F$ & $\mathbf{T}$ & $S$ & \\
\hline \multirow[t]{6}{*}{ Sheep } & D-spacing (nm) & $\begin{array}{l}64.96 \\
(0.09)\end{array}$ & $\begin{array}{l}65.16 \\
(0.04)\end{array}$ & $\begin{array}{l}65.58 \\
(0.02)\end{array}$ & $\begin{array}{l}65.36 \\
(0.04)\end{array}$ & $\begin{array}{l}65.42 \\
(0.01)\end{array}$ \\
\hline & $P$-value & $<0.05$ & $<0.05$ & $<0.05$ & 0.06 & - \\
\hline & Fibril diameter (nm) & $\begin{array}{l}37.08 \\
(0.23)\end{array}$ & $\begin{array}{l}36.44 \\
(0.24)\end{array}$ & $\begin{array}{l}38.27 \\
(0.32)\end{array}$ & $\begin{array}{l}36.68 \\
(0.20)\end{array}$ & $\begin{array}{l}35.52 \\
(0.15)\end{array}$ \\
\hline & P-value & $<0.05$ & $<0.05$ & $<0.05$ & $<0.05$ & - \\
\hline & $\begin{array}{l}\text { Fibril diameter } \\
\text { distribution (nm) }\end{array}$ & $\begin{array}{l}5.40 \\
(0.45)\end{array}$ & $\begin{array}{l}5.22 \\
(0.20)\end{array}$ & $\begin{array}{l}3.99 \\
(0.34)\end{array}$ & $\begin{array}{l}3.50 \\
(0.36)\end{array}$ & $\begin{array}{l}4.83 \\
(0.31)\end{array}$ \\
\hline & $P$-value & $<0.05$ & $<0.05$ & $<0.05$ & $<0.05$ & - \\
\hline \multirow[t]{6}{*}{ Cat } & D-spacing (nm) & $\begin{array}{l}64.71 \\
(0.06)\end{array}$ & $\begin{array}{l}64.83 \\
(0.06)\end{array}$ & $\begin{array}{l}65.30 \\
(0.11)\end{array}$ & $\begin{array}{l}65.15 \\
(0.01)\end{array}$ & $\begin{array}{l}65.22 \\
(0.01)\end{array}$ \\
\hline & $P$-value & $<0.05$ & $<0.05$ & 0.29 & 0.07 & - \\
\hline & Fibril diameter (nm) & $\begin{array}{l}40.50 \\
(0.25)\end{array}$ & $\begin{array}{l}39.18 \\
(0.31)\end{array}$ & $\begin{array}{l}41.73 \\
(0.48)\end{array}$ & $\begin{array}{l}38.50 \\
(0.23)\end{array}$ & $\begin{array}{l}37.26 \\
(0.24)\end{array}$ \\
\hline & $P$-value & $<0.05$ & $<0.05$ & $<0.05$ & $<0.05$ & - \\
\hline & $\begin{array}{l}\text { Fibril diameter } \\
\text { distribution (nm) }\end{array}$ & $\begin{array}{l}4.89 \\
(0.28)\end{array}$ & $\begin{array}{l}5.01 \\
(0.21)\end{array}$ & $\begin{array}{l}4.21 \\
(0.37)\end{array}$ & $\begin{array}{l}3.23 \\
(0.37)\end{array}$ & $\begin{array}{l}4.53 \\
(0.12)\end{array}$ \\
\hline & $P$-value & $<0.05$ & $<0.05$ & $<0.05$ & $<0.05$ & - \\
\hline
\end{tabular}




\section{5\% Glutaraldehyde}

Relative to the controls, fibril diameters and fibril diameter distributions for both the sheep and cats' corneas preserved in $5 \%$ glutaraldehyde were significantly higher $(P<0.05)$. However, they had significantly lower $D$-spacing than the controls $(P<0.05)$.

\section{$10 \%$ Formalin}

Similar to the glutaraldehyde treated samples, the corneas preserved in $10 \%$ formalin had fibril diameters and fibril diameter distribution values that were significantly higher than the controls and D-spacing significantly lower than the controls $(P<0.05)$.

\section{Triton X}

The fibril diameters for both the cat and sheep corneas preserved in Triton $\mathrm{X}$ were significantly greater ( $\mathrm{P}$ $<0.05)$ than those of the controls and the largest recorded in the experiments. The fibril diameter distributions, however, were significantly lower than those of the controls. The D-spacing was increased in both the cat and the sheep corneas but this was only significant in the latter $(P<0.05)$.

\section{$0.9 \%$ saline}

Of all the preservatives, the values of the samples in $0.9 \%$ saline most closely matched those of the controls with no significant differences between the D-spacing of the sheep and cats' corneas compared to the controls. However, fibril diameters in both sheep and cats' corneas were significantly higher $(\mathrm{P}<$ 0.05 ) and diameter distributions significantly lower than in the controls.

\section{Transmission Electron Microscopy}

It should be noted that the steps used in processing the samples for TEM affect the morphology of collagen ${ }^{17}$ and it was not therefore possible to perform quantitative comparisons of results obtained by SAXS analysis and TEM. However, subjective morphological assessment of the TEM images supported the SAXS data showing, for example, that fibril diameter in the glutaraldehyde, formalin and Triton $\mathrm{X}$ samples differed clearly from that of the saline and control corneas (Figure 4 and 5). Similarly, electron microscopy revealed only minor differences between the controls, stored frozen before being fixed in $5 \%$ glutaraldehyde for TEM processing, and the samples preserved in $10 \%$ formalin and $5 \%$ glutaraldehyde in respect of interfibrillar spacing/distance, number of fibrils in a given area and the amount of interfibrillar matrix. However, very marked differences were seen between the controls and the samples preserved in Triton $X$ and saline before they were fixed in $5 \%$ glutaraldehyde for TEM processing (Figure 4 and 5). In the sections of the $10 \%$ formalin and $5 \%$ glutaraldehyde preserved corneas where epithelial and 
endothelial cells were visible, their morphology appeared normal. Cells, however, were not seen in sections showing the anterior and posterior areas of corneas preserved in Triton $\mathrm{X}$ and saline.

\section{Transmission Electron Microscope Image Processing}

Although it was not possible to perform quantitative comparisons of results obtained by SAXS analysis and TEM (above), in measuring diameters of fibrils seen in cross-section in the TEM sections, a pattern of fibril diameter distribution similar to that in the SAXS study was noted (Figure 6). The diameters of the fibrils in the normal control were significantly smaller than those in the samples preserved in $5 \%$ glutaraldehyde, 10\% formalin, Triton X and PBS, for both the sheep and cats' corneas (Table 2).

Table 2

esults from the transmission electron microscopy image analysis to determine average (standard deviation) fibril diameter of sheep and cats' corneas treated with $5 \%$ glutaraldehyde (G), $10 \%$ formalin (F), Triton X (T), and $0.9 \%$ saline (S) followed by fixation in Karnovsky's fixative and processing for TEM. P-

values relate to a significance test between the various preservatives relative to the control untreated cornea sample values (C).

\begin{tabular}{|c|c|c|c|c|c|c|}
\hline \multirow[t]{2}{*}{ Species } & \multirow{2}{*}{$\begin{array}{l}\text { Collagen } \\
\text { Properties }\end{array}$} & \multicolumn{4}{|c|}{ Preservative } & \multirow{2}{*}{$\begin{array}{l}\text { Control } \\
\text { C }\end{array}$} \\
\hline & & G & $\mathbf{F}$ & $\mathrm{T}$ & $S$ & \\
\hline \multirow[t]{2}{*}{ Sheep } & $\begin{array}{l}\text { Fibril Diameter } \\
(\mathrm{nm})\end{array}$ & $\begin{array}{l}35.88 \\
(3.27)\end{array}$ & $\begin{array}{l}38.35 \\
(3.28)\end{array}$ & $\begin{array}{l}52.37 \\
(10.51)\end{array}$ & $\begin{array}{l}40.81 \\
(5.68)\end{array}$ & $\begin{array}{l}32.10 \\
(2.70)\end{array}$ \\
\hline & P-value & $<0.05$ & $<0.05$ & $<0.05$ & $<0.05$ & - \\
\hline \multirow[t]{2}{*}{ Cat } & $\begin{array}{l}\text { Fibril Diameter } \\
(\mathrm{nm})\end{array}$ & $\begin{array}{l}43.12 \\
(5.12)\end{array}$ & $\begin{array}{l}47.38 \\
(5.74)\end{array}$ & $\begin{array}{l}45.69 \\
(7.65)\end{array}$ & $\begin{array}{l}44.29 \\
(6.43)\end{array}$ & $\begin{array}{l}42.07 \\
(4.13)\end{array}$ \\
\hline & $P$-value & $<0.05$ & $<0.05$ & $<0.05$ & $<0.05$ & - \\
\hline
\end{tabular}

\section{Discussion}

While sophisticated modern techniques enable more detailed analysis of the nanostructure of materials, the processing required before analysis often leads to significant changes being introduced in the shapes and sizes of the different tissue components. For example, tissues prepared for TEM are changed during fixation and then again during the dehydration step required before embedding. Also, there are a variety of resins available for embedding, each of which alter the nanostructure of tissue components in different ways.(20) Although there is reasonable data on the changes brought about in tissues by processing for $\operatorname{TEM}(19,20,24,25)$ there is little and only fragmented data on the effects of tissue processing on SAXS analysis.

This study has shown that commonly used preservatives introduce significant changes in the ultrastructure of both sheep and cats' corneal collagen parameters as determined by SAXS analysis. Formalin and glutaraldehyde resulted in significantly decreased D-spacing and increased collagen fibril diameters in the corneas of the sheep and cats studied. Both formalin and glutaraldehyde are relatively small molecules, which can readily penetrate collagen and form cross linkages that bind the collagen 
molecules together and would decrease the $D$-spacing. Before such cross links can form, however, it has been suggested that the hypotonic fixative solution moves into the fibrils and causes them to swell.(20) The swollen fibrils would be expected to be larger and lead to increased fibril diameter which is consistent with our findings on samples stored in formalin and glutaraldehyde.

With TEM, the fibrils in the $5 \%$ glutaraldehyde and $10 \%$ formalin samples appeared to have relatively uniform diameters with short-range order interfibrillar spacing. This has been shown to be essential for optical transparency $(2,3)$ which was noted in these samples in the transparency testing. Further, the epithelial and endothelial cells in corneas preserved in $5 \%$ glutaraldehyde and $10 \%$ formalin appeared normal, which is also a requirement for corneal transparency. The presence of specialized water-soluble structural proteins (crystalline proteins) and high levels of enzymes such as aldehyde dehydrogenase and transketolase in the cytoplasm of the epithelial cells(26) results in refractive indices of the cytoplasm and cell organelles that are within a range that does not produce scattering of light.

Triton $\mathrm{X}$ is a non-ionic detergent used in tissue engineering to produce implantable acellular matrix scaffolds from heart valves,(27) tendons(28) and ligaments.(29) In removing proteoglycans and the intercellular matrix between collagen fibrils, the Triton X likely facilitated the entry of its $0.9 \%$ saline diluent into fibrils causing them to swell and increase the fibril diameter as seen in the SAXS analyses of the samples. In TEM sections, the fibrils also appeared larger and there was considerable variation in interfibrillar spacing, very irregular packing and poor short-range order, all consistent with the marked lack of transparency noted in the transparency testing.

Storage in $0.9 \%$ saline only resulted in a significant increase in collagen fibril diameter and fibril diameter distribution. This most likely was because the cornea is normally maintained in a slightly dehydrated state by the endothelial cells on its inner surface. $(30,31)$ The $0.9 \%$ saline used in the study would thus be relatively hypotonic to the cornea and, with the loss of endothelial and epithelial cells noted, water would have moved into the corneal samples increasing the hydration status of the fibrils and causing them to swell. $(9,32)$ The resultant mild corneal odema would also have interfered with the optimal regular spacing and size of the fibrils required for normal transparency. $(33,34)$ The mild odema induced by $0.9 \%$ saline explains both the loss of clarity of the cornea noted in the transparency test and the larger fibril diameters and their distribution recorded by SAXS and TEM analysis.

\section{Conclusions}

In conclusion, this study has shown that commonly used preservatives bring about significant changes in collagen parameters (D-spacing and fibril diameter) measured by SAXS. It is important these changes are recognized so that comparable data can be obtained from studies using SAXS analysis on tissues processed in different ways.

\section{List Of Abbreviations}


SAXS small angle $x$-ray scattering

TEM transmission electron microscopy

\section{Declarations}

\section{Ethics approval and consent to participate}

Not applicable.

\section{Consent for publication}

Not applicable.

\section{Availability of data and materials}

The datasets used and/or analysed during the current study are available from the corresponding author on reasonable request.

\section{Competing interests}

The authors declare that they have no competing interests.

\section{Funding}

The author(s) received the following financial support for the research, authorship and/or publication of this article: The New Zealand Synchrotron Group paid for beamtime, travel and accommodation for the SAXS measurements.

\section{Authors' contributions}

SK collected and analysed the small angle x-ray scattering data and was a major contributor in writing the manuscript. LP collected and analysed the transmission electron microscopy images. JS analysed the transmission electron microscopy measurements and contributed in writing the manuscript. FN developed the image analysis tool and analysed images. HW assisted with small angle $\mathrm{x}$-ray scattering data collection and analysis. PK was a major contributor in writing the manuscript. All authors read and approved the final manuscript.

\section{Acknowledgements}

Dr's Nigel Kirby, Stephen Mudie and Tim Ryan from the SAXS/WAXS beamline at the Australian Synchrotron, part of ANSTO, are thanked for their assistance. The New Zealand Synchrotron Group provided funding and Dr Fernanda Castillo Alcala from Massey Veterinary School and Mr. Philip Taylor at Ovation Abattoir provided samples. 


\section{References}

1. Yang W, Sherman VR, Gludovatz B, Schaible E, Stewart P, Ritchie RO, et al. On the tear resistance of skin. Nat Commun. 2015;6:6649-.

2. Meek KM, Boote C. The organization of collagen in the corneal stroma. Exp Eye Res. 2004;78(3):50312.

3. Meek KM, Knupp C. Corneal structure and transparency. Prog Retin Eye Res. 2015;49:1-16.

4. Glatter O, Kratky O. Small Angle X-ray Scattering. London: Academic; 1982. p. 220-224.

5. Kelly S, Edmonds, R., Cooper, S., Sizeland, K., Wells, H., Ryan, T., Kirby, N., Mudie S. and Haverkamp R. Mapping Tear Strength and Collagen Fibril Orientation in Bovine, Ovine and Cervine Hides and Skins. J Am Chem Soc. 2018;113(1):1-11.

6. Kelly SJ, Wells HC, Sizeland KH, Kirby N, Edmonds RL, Ryan T, et al. Artificially modified collagen fibril orientation affects leather tear strength. J Sci Agric Food. 2018;98(9):3524-3531.

7. Sizeland KH, Wells HC, Norris GE, Edmonds RL, Kirby N, Hawley A, et al. Collagen D-spacing and the effect of fat liquor addition. J Am Leather Chem Assoc 2015;110(3):66-71.

8. Wells HC, Edmonds RL, Kirby N, Hawley A, Mudie ST, Haverkamp RG. Collagen fibril diameter and leather strength. J Agric Food Chem. 2013;61(47):11524-31.

9. Fratzl P, Fratzl-Zelman N, Klaushofer K. Collagen packing and mineralization: an x-ray scattering inverstigation of turkey leg tendon. Biophys J. 1993;64:260-6.

10. Price RI, Lees S, Kirschner DA. X-ray diffraction analysis of tendon collagen at ambient and cryogenic temperatures: Role of hydration. Int J Biol Macromol. 1997;20(1):23-33.

11. Boote C, Kamma-Lorger CS, Hayes S, Harris J, Burghammer M, Hiller J, et al. Quantification of collagen organization in the peripheral human cornea at micron-scale resolution. Biophys $\mathrm{J}$. 2011;101(1):33-42.

12. de la Cuesta FB, Wenger MPE, Bean RJ, Bozec L, Horton MA, Robinson IK. Coherent X-ray diffraction from collagenous soft tissues. Proc Natl Acad Sci USA. 2009;106(36):15297-301.

13. McCally RL, Farrell RA. Structural implications of small-angle light scattering from cornea. Exp Eye Res. 1982;34(1):99-113.

14. Quantock AJ, Boote C, Young RD, Hayes S, Tanioka H, Kawasaki S, et al. Small-angle fibre diffraction studies of corneal matrix structure: A depth-profiled investigation of the human eye-bank cornea. $J$ App Crystallogr. 2007;40(SUPPL. 1):s335-s40.

15. Fratzl P, Daxer A. Structural transformation of collagen fibrils in corneal stroma during drying. An xray scattering study. Biophys J. 1993;64(4):1210-4.

16. Meek KM, Quantock AJ. The use of X-ray scattering techniques to quantify the orientation and distribution of collagen in the corneal stroma. Prog Retin Eye Res. 2001;20(1):95-137.

17. Gyi TJ, Meek KM, Elliott GF. Collagen interfibrillar distances in corneal stroma using synchrotron X-ray diffraction: a species study. Int J Biol Macromol. 1988;10(5):265-9. 
18. Bolfa P, Kelly SJ, Wells HC, Sizeland KH, Scott EM, Kirby N, et al. Tropical Keratopathy (Florida Spots) in Cats. Vet Pathol. 2018;55(6):861-70.

19. Akhtar S. Effect of processing methods for transmission electron microscopy on corneal collagen fibrils diameter and spacing. Microsc Res Techniq. 2012;75(10):1420-4.

20. Fullwood N, Meek K. A synchrotron X-ray study of the changes occurring in the corneal stroma during processing for electron microscopy. J Microsc. 1993;169(1):53-60.

21. Turunen MJ, Khayyeri $\mathrm{H}$, Guizar-Sicairos $\mathrm{M}$, Isaksson $\mathrm{H}$. Effects of tissue fixation and dehydration on tendon collagen nanostructure. J Struct Biol. 2017;199(3):209-215.

22. Boote C, Hayes S, Abahussin M, Meek KM. Mapping Collagen Organization in the Human Cornea: Left and Right Eyes Are Structurally Distinct. Invest Ophthalmol Vis Sci. 2006;47(3):901-8.

23. Ilavsky J, Jemian PR. Irena: tool suite for modeling and analysis of small-angle scattering. J Appl Crystallogr. 2009;42:347-53.

24. Craig AS, Robertson JG, Parry DAD. Preservation of corneal collagen fibril structure using lowtemperature procedures for electron microscopy. J Ultrastruct Mol Struct Res. 1986;96(1):172-5.

25. Meek KM, Chapman JA. Glutaraldehyde-induced Changes in the Axially Projected Fine Structure of Collagen Fibrils. J MolBio. 1985;185(2):359-70.

26. Jester JV. Corneal crystallins and the development of cellular transparency. Semin Cell Dev Biol. 2008;19(2):82-93.

27. Grauss RW, Hazekamp MG, Oppenhuizen F, van Munsteren CJ, Gittenberger-de Groot AC, DeRuiter MC. Histological evaluation of decellularised porcine aortic valves: matrix changes due to different decellularisation methods. Eur J Cardiothorac Surg. 2005;27(4):566-71.

28. Dahl SL, Koh J, Prabhakar V, Niklason LE. Decellularized native and engineered arterial scaffolds for transplantation. Cell transplantation. 2003;12(6):659-66.

29. Cartmell JS, Dunn MG. Development of cell-seeded patellar tendon allografts for anterior cruciate ligament reconstruction. Tissue Eng. 2004;10(7-8):1065-75.

30. Qazi Y, Wong G, Monson B, Stringham J, Ambati BK. Corneal transparency: genesis, maintenance and dysfunction. Brain Res Bull. 2010;81(2-3):198-210.

31. Maurice DM. The location of the fluid pump in the cornea. J Physiol. 1972;221(1):43-54.

32. Meek K, Fullwood N, Cooke P, Elliott G, Maurice D, Quantock A, et al. Synchrotron x-ray diffraction studies of the cornea, with implications for stromal hydration. Biophys J. 1991;60(2):467-74.

33. Mazzotta C, Balestrazzi A, Traversi C, Baiocchi S, Caporossi T, Tommasi C, et al. Treatment of progressive keratoconus by riboflavin-UVA-induced cross-linking of corneal collagen: ultrastructural analysis by Heidelberg Retinal Tomograph II in vivo confocal microscopy in humans. Cornea. 2007;26(4):390-7.

34. Meek KM, Dennis S, Khan S. Changes in the Refractive Index of the Stroma and Its Extrafibrillar Matrix When the Cornea Swells. Biophys J. 2003;85(4):2205-12. 

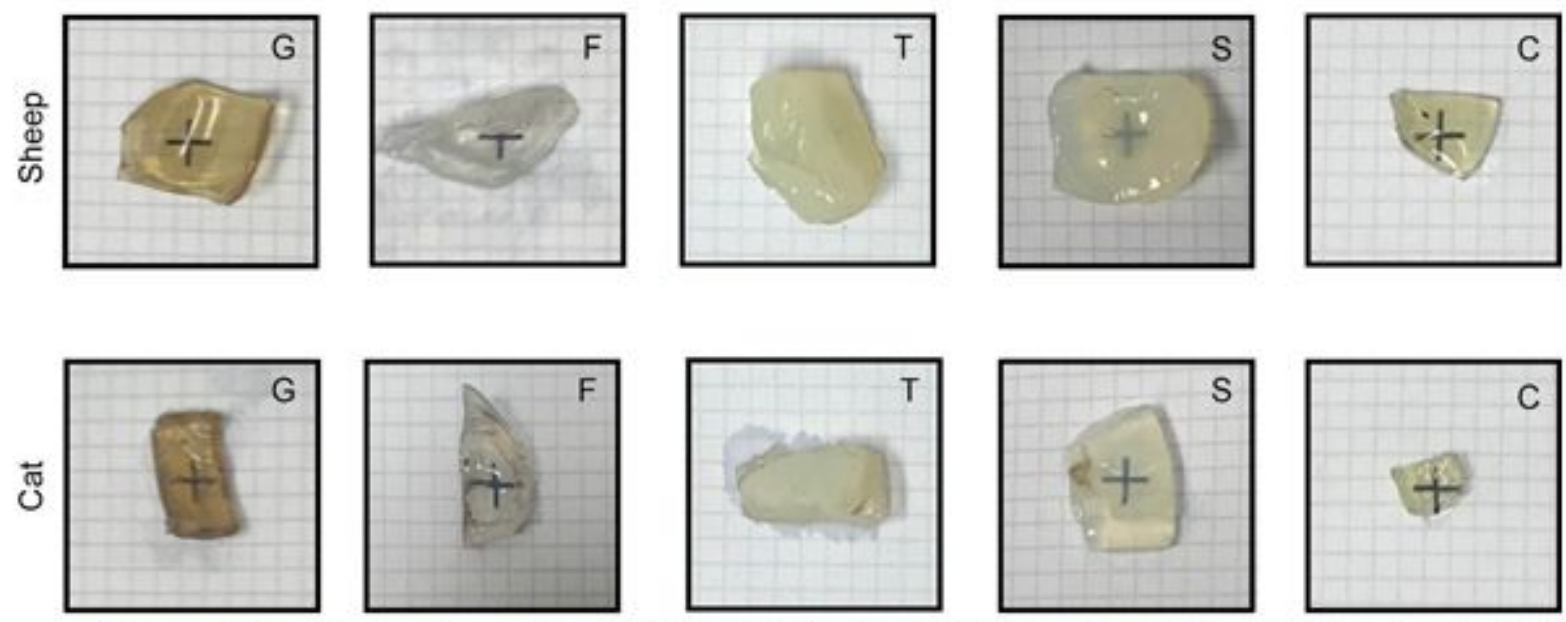

Preservatives: Frozen, thawed control $(\mathrm{C})$, glutaraldehyde $(\mathrm{G})$, formalin (F), triton $\mathrm{X}(\mathrm{T})$ and saline $(\mathrm{S})$.

\section{Figure 1}

Subjective assessment of the transparency of sheep and cats' preserved corneas on a $4 \mathrm{~mm}$ grid.

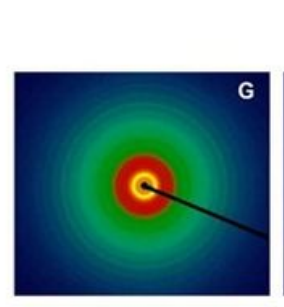

\section{Sheep Cornea}

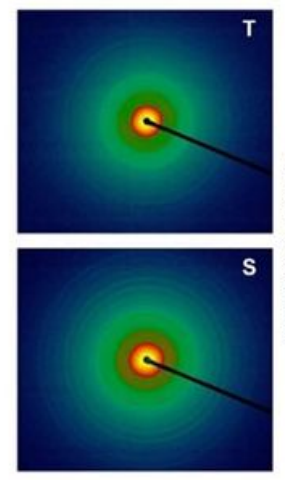

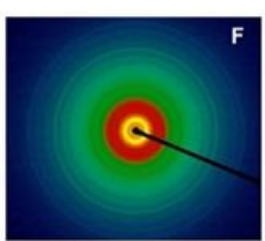
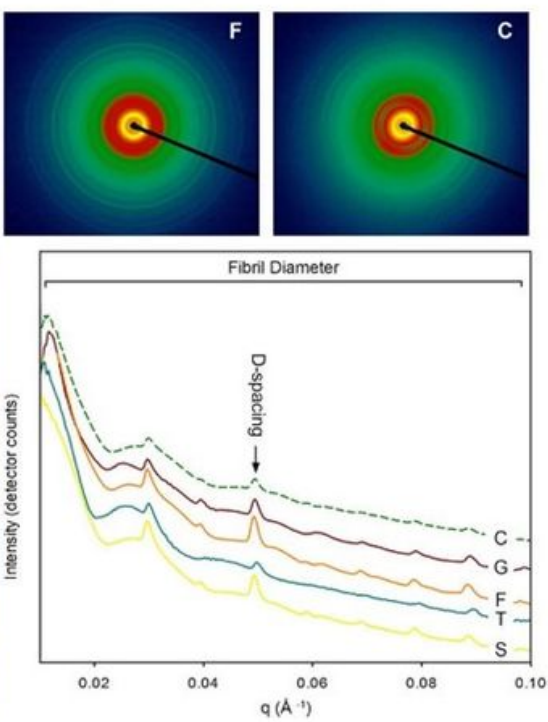

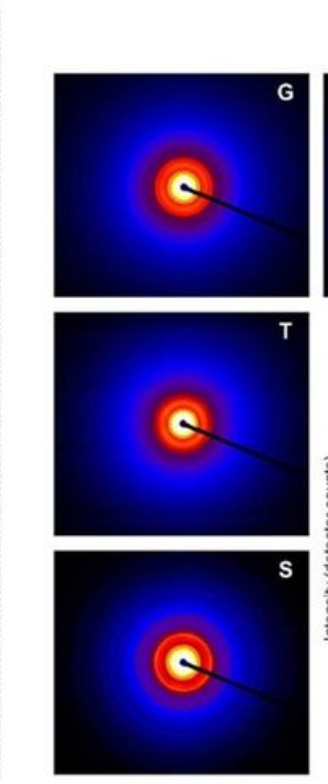

Cat Cornea
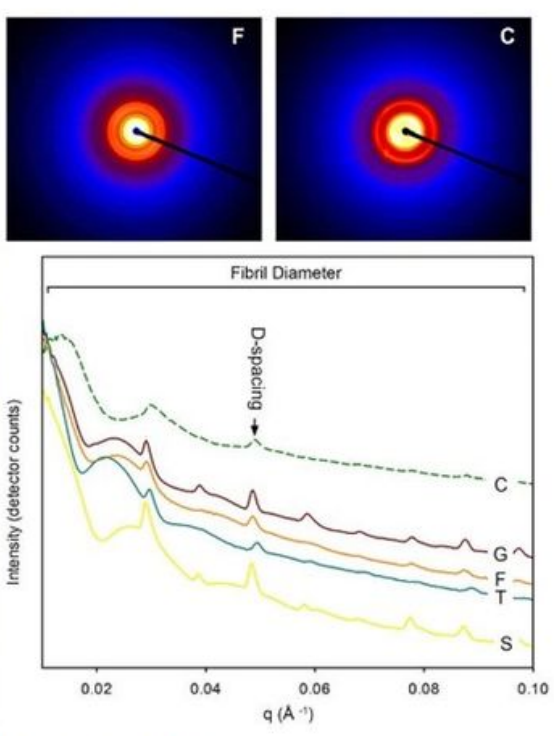

Preservatives: Frozen, thawed control $(C)$, glutaraldehyde $(G)$, formalin $(F)$, triton $X(T)$ and saline $(S)$.

\section{Figure 2}

Photo images of 2D small angle X-ray scattering patterns produced by frozen and thawed control corneas and the preserved corneas. The graph shows the intensity profiles over the measured q-range for 
all the samples. Arrow indicates peak $(0.045-0.055 \AA$ - 1$)$ used to determine D-spacing and the full qrange $(0.01-0.1 \AA-1)$ for the fibril diameter.
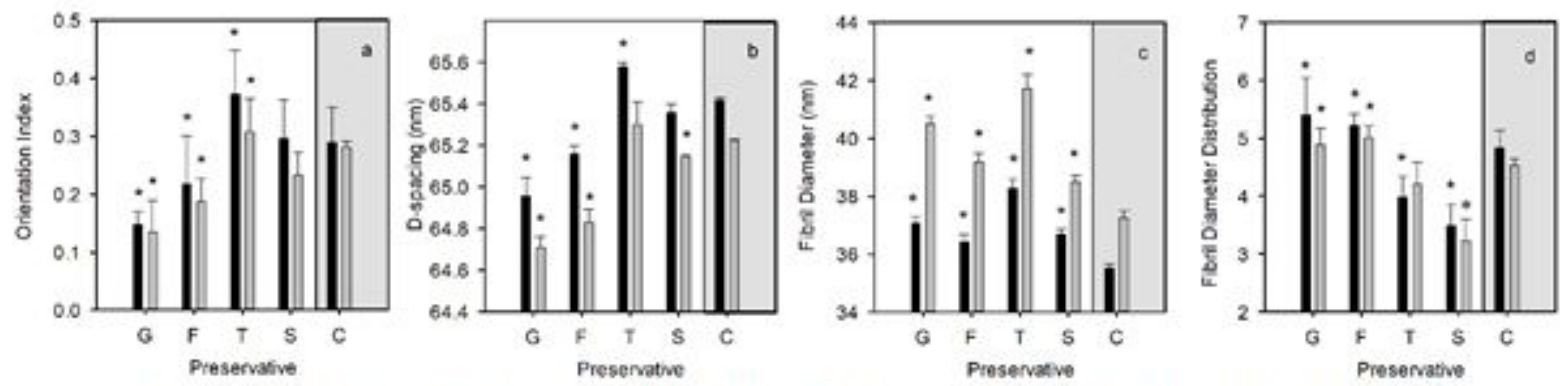

Procoratives: Frozon, thawed control (C), glutaralcehyde (G), formalin (F), triton $X(T)$ and saline (S).

\section{Figure 3}

Mean and standard deviation measurements from the sheep (black) and the cat (gray) corneas treated with preservatives or frozen to act as a control. Parameters measured were: (a) Orientation indices showing the relative fibril alignment, (b) D-spacing determined by the 5th order diffraction peak location, (c) fibril diameter from the total non-negative least square and cylinder AR models, and (d) the fibril diameter distribution measured by the full width half maximum of the diameters determined from the models mentioned above. An * indicates values that were significantly different from the control. 

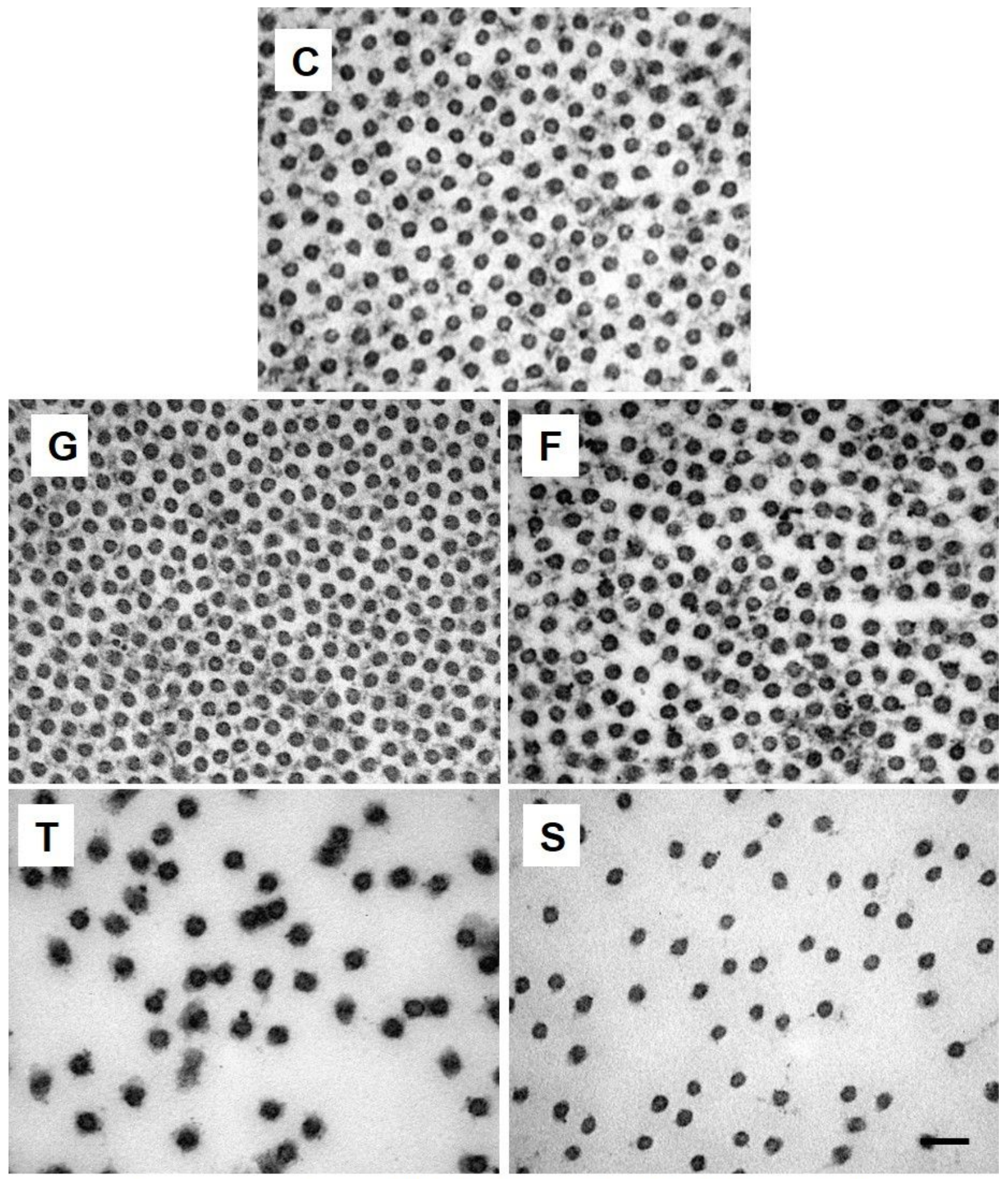

Preservatives: Frozen, thawed control $(C)$, glutaraldehyde $(G)$, formalin $(F)$, triton $X(T)$ and saline $(S)$.

Figure 4

Transmission electron micrographs (TEM) depicting collagen fibril cross-sections in the stroma of sheep corneas freeze/thawed or preserved for 5 days followed by fixation in Karnovsky's fixative and processing for TEM. 

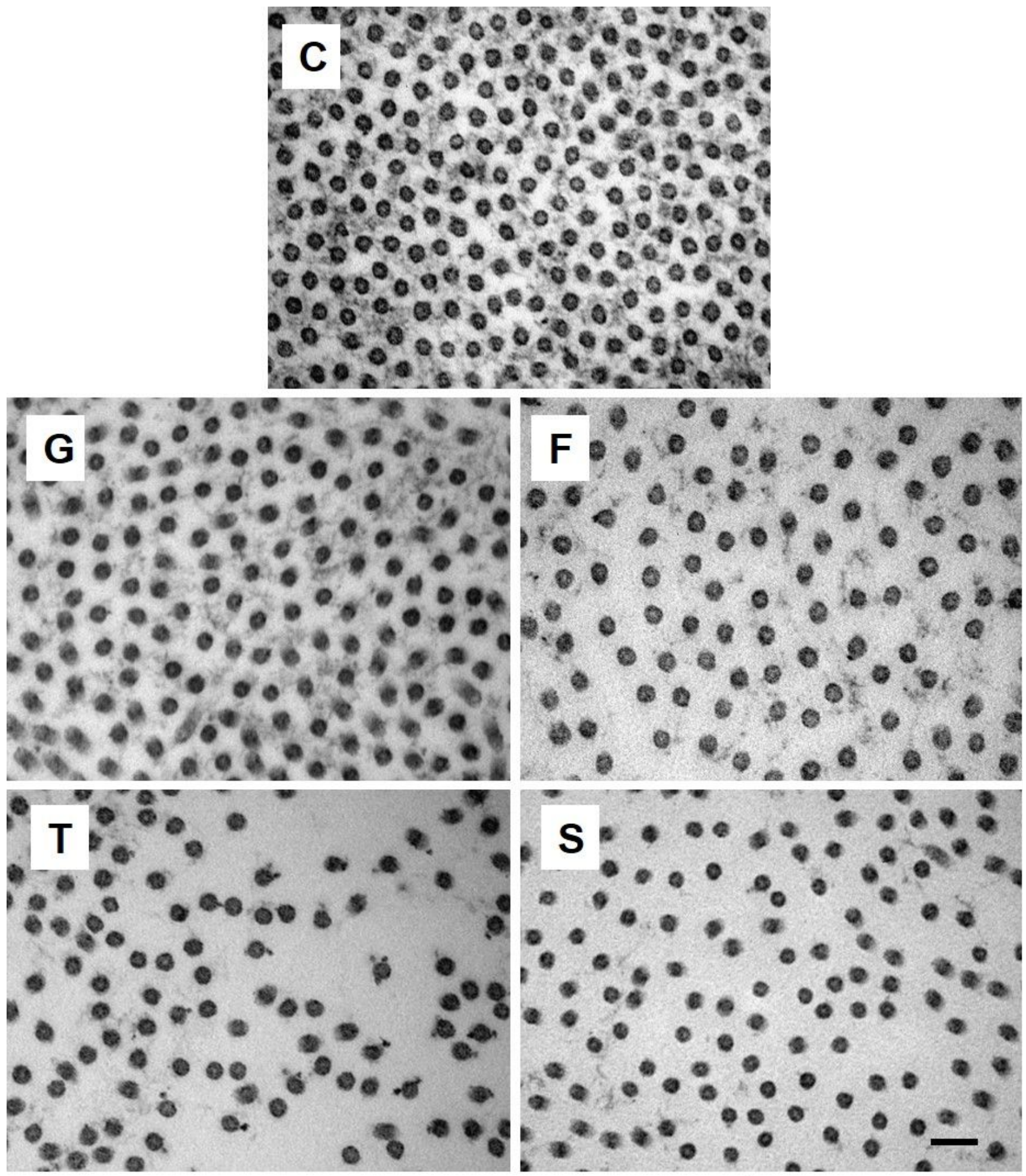

Preservatives: Frozen, thawed control $(C)$, glutaraldehyde $(G)$, formalin $(F)$, triton $X(T)$ and saline $(S)$.

Figure 5

Transmission electron micrographs (TEM) depicting collagen fibril cross-sections in the stroma of cat corneas freeze/thawed or preserved for 5 days followed by fixation in Karnovsky's fixative and processing for TEM. 


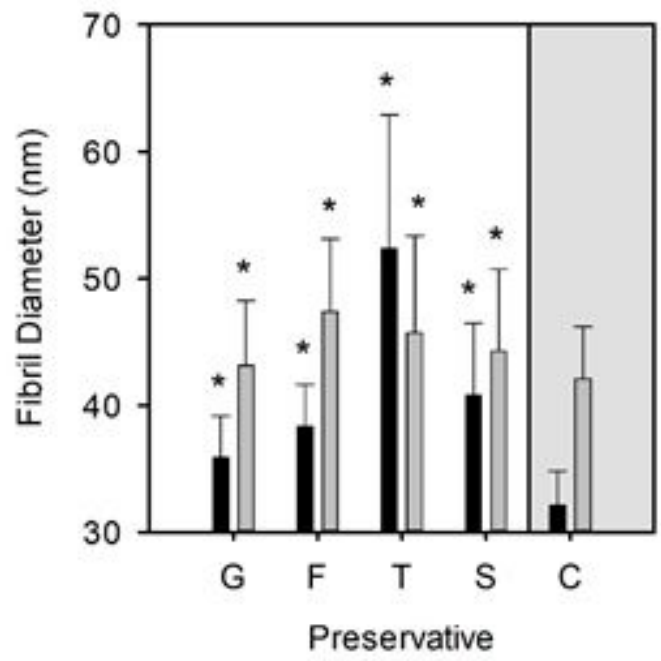

Preservatives: Frozen, thawed control $(C)$, glutaraldehyde $(G)$, formalin $(F)$, triton $X(T)$ and saline $(S)$.

Figure 6

Means and standard deviations of fibril diameters of collagen in corneas determined by analysis of cross-sectional views of the stroma observed by transmission electron micrographs. An * indicates values that were significantly different from the control. 